\title{
Effect of perinatal glucocorticoids on vascular health and disease
}

\author{
Aaron R. Millage ${ }^{1}$, Mariam S. Latuga ${ }^{2}$ and Judy L. Aschner ${ }^{1,2}$
}

The benefits of antenatal glucocorticoids are now firmly established in the perinatal management of threatened preterm birth. Postnatal glucocorticoid therapy, however, remains controversial in neonatal medicine, with the need to balance short-term physiological benefits against the potential for long-term adverse consequences. This review focuses on the vascular effects of prenatal and postnatal glucocorticoids, synthesizing data from both experimental animal models and human infants with the goal of better appreciation of the short and long-term effects of these commonly used drugs. Due to their widespread and varied use, improved understanding of the cellular and molecular impact of glucocorticoids is important in guiding current practice and future research.

G lucocorticoids play an important role in perinatal and neonatal medicine. Clinical benefits associated with glucocorticoids include, but are not limited to, antenatal administration for lung, brain and gastrointestinal protection of preterm infants, and postnatal use in ventilator dependence and pressor-resistant hypotension. The precise mechanisms underlying the beneficial effects of perinatal glucocorticoids have not yet been clarified. The genomic actions of glucocorticoids occur via binding to the glucocorticoid receptor, a member of the nuclear receptor family of ligand-dependent transcription factors (1). After activation by its ligand, the receptor can act as a transcription factor and alter the expression of specific target genes. Whether specific actions of glucocorticoids occur via this mechanism or via other nongenomic effects is unclear given the variety of uses and lack of mechanistic studies in specific disease models. What is clear, however, is that from adult neurologic and cardiovascular disorders to chronic glucocorticoid-induced hypertension, steroids have a significant impact on the human vascular system (1-3).

\section{MECHANISMS OF ACTION}

The effects of glucocorticoids on vascular health and dysfunction may be mediated in part by activation of endothelial nitric oxide synthase (eNOS). Dysfunction of eNOS or its downstream signaling targets has been implicated in many disease states. Endothelial NOS catalyzes the formation of NO and citrulline from the nitrogens of L-arginine via a complex oxidation-reduction reaction, requiring molecular oxygen and NADPH plus numerous cofactors (flavin adenine dinucleotide (FAD), Flavin mononucleotide (FMN), heme, and tetrahydrobiopterin), as well as the activator calmodulin (4). Nitric oxide diffuses extracellularly to bind with soluble guanylyl cyclase in neighboring smooth muscle cells to increase cyclic GMP concentrations. Cyclic GMP activates G kinase and decreases smooth muscle cell intracellular calcium levels, eliciting relaxation in most conductance vessels. Activation of eNOS and release of NO have been shown to play important roles in normal neonatal circulatory transition; however the role of NO in various neonatal disease states, such as bronchopulmonary dysplasia (BPD), chronic pulmonary hypertension associated with BPD, neonatal sepsis, and necrotizing enterocolitis, are not much well understood (5). How the vascular processes involved in these physiologic and pathologic states may be influenced by steroid administration is incompletely understood, but is important that given the protection conferred by antenatal steroids and the clinical effects of postnatal steroids.

Vascular responses are known to be influenced by eNOS expression and activity. Antenatal dexamethasone (DEX) treatment increases eNOS expression in large vessel endothelium and large airway and small airway epithelium of fetal rat lungs (6). In rat models of congenital diaphragmatic hernia in which eNOS protein levels in the lung are decreased, maternal antenatal DEX administration results in offspring lung tissue that contained eNOS protein amounts equal to that of control, noncongenital diaphragmatic hernia animals (7). Antenatal betamethasone (BMZ) stimulates an increase in eNOS protein levels in lambs born with pulmonary hypertension induced by fetal ductal ligation (8). Similarly, repeat doses of antenatal BMZ increased total amounts of eNOS protein in the lung of newborn lambs (9). Of note, steroids also decrease baseline values of IL6 and reactive oxidative species suggesting other mechanisms may contribute to improved pulmonary outcomes following antenatal BMZ (10). Thus, through its effect on pulmonary vascular physiology, biochemistry and molecular signaling, antenatal steroids improve the pulmonary transition and adaptation at birth in a number of animal models.

Given the pivotal role of eNOS in vascular homeostasis, it is also important to consider the impact of steroids on eNOS cofactors that have been implicated in disease processes 


\section{Perinatal steroids and the vasculature}

of vascular dysfunction. Tetrahydrobiopterin $\left(\mathrm{BH}_{4}\right)$ is one such cofactor or stabilizer of eNOS, which is altered by corticosteroid administration. In adult rats, glucocorticoids downregulate guanosine triphosphate cyclohydrolase, the generator of tetrahydrobiopterin, causing attenuation of eNOS-dependent regulation of vascular contractility (11). Glucocorticoids are known to interact with Hsp90, a molecular chaperone required for eNOS phosphorylation and coupled eNOS activity (12). In a lamb model of pulmonary hypertension, antenatal BMZ restored Hsp90 interactions with eNOS in hypertensive pulmonary artery endothelial cells and corrected the increase in superoxide levels and decrease in NO bioavailability, resulting in decreased oxidative stress in pulmonary artery endothelial cells and improved eNOS protein expression (8). Steroids may affect other eNOS cofactors implicated in dysregulation of vascular tone such as caveolin-1 and calmodulin, however their contribution requires further study (13).

Synthetic glucocorticoids, specifically DEX and BMZ, cross the placenta without degradation by 11 beta-hydroxysteroid dehydrogenase and reach significant pharmacological levels in the fetus, in the range of $30-50 \%$ of the maternal levels (14). The mechanisms underlying the clinical benefits of antenatal corticosteroids may, at least in part, be related to their effects on the fetal vasculature. The vascular effects of steroids are described below according to their pre and postnatal uses, with separate consideration of the pulmonary and systemic vascular effects of various steroid preparations and dosing regimens.

\section{ANTENATAL VASCULAR EFFECTS}

Antenatal steroids have been shown to have many beneficial effects on the fetus. In multiple randomized controlled trials and meta-analyses, maternal administration of a single course of antenatal corticosteroids, commonly BMZ or DEX, is associated with an overall reduction in neonatal death and morbidity, including respiratory distress syndrome, intraventricular hemorrhage, NEC, and neonatal intensive care unit admissions $(15,16)$. Routine clinical use of antenatal glucocorticoids has previously been limited to mothers with threatened or impending preterm birth between 24 and $34 \mathrm{wk}$ of gestation (17). However, infants born between 18 and $23 \mathrm{wk}$ gestation may also benefit from antenatal corticosteroids with decreased mortality and improved neurodevelopmental outcomes (18). More recently, it has been demonstrated that antenatal BMZ treatment decreases respiratory morbidity and NICU admission rates among late preterm infants born between 34 and $36 \mathrm{wk}$ of gestation (19). Glucocorticoids may have maximal effect during a critical window of development, an important area for future research.

Infants with congenital pulmonary abnormalities may also benefit from antenatal BMZ (20). Studies on the potential advantages of antenatal glucocorticoid in other clinical scenarios including fetuses with antenatally diagnosed congenital diaphragmatic hernia (20) and fetuses of diabetic mothers at or near term are needed.

\section{Pulmonary Effects of Antenatal Steroids}

Prenatal glucocorticoids have significant maturational effects on the developing fetal lung, which include enhanced alveolar differentiation, thinning of alveolar septae and capillary walls, and upregulation of surfactant production $(21,22)$. In fetal rat and lamb models of pulmonary development, antenatal glucocorticoids enhance normal development with increased antioxidant activity and decreased formation of reactive oxygen species $(6,7)$. In a premature lamb model of lipopolysaccharide induced chorioamnionitis, antenatal steroids provide partial recovery of lung structure via the sonic hedgehog pathway (23).

Antenatal corticosteroids enhance fetal pulmonary adaptation at birth, although the mechanism is unclear. In a late gestation lamb model, fetal pulmonary vascular reactivity is increased by antenatal corticosteroid administration in response to vasodilatory stimuli, such as catecholamines, prostaglandins, and NO (24). In a preterm lamb model, antenatal corticosteroids specifically enhance fetal pulmonary blood flow, an effect that does not persist after birth (25). In nearterm lambs with hypoplastic lungs, antenatal steroids return pulmonary blood flow to control levels, restoring the impaired perinatal adaptation of the pulmonary circulation in this model (26). Analysis of Doppler indices in extremely premature human fetuses following maternal BMZ administration suggests decreased pulmonary vascular resistance (27). Thus, the effect of antenatal corticosteroids on pulmonary blood flow may vary based on gestation and perinatal cardiopulmonary physiology.

\section{Systemic Effects of Antenatal Steroids}

Within days of maternal steroid administration, changes are observed in human fetal hemodynamics $(28,29)$. Corticosteroids dilate the human umbilical circulation both in vivo and in vitro and may blunt fetal response to hypoxia $(30,31)$. Corticosteroids increase fetal systemic blood pressure while cerebral blood flow is decreased due to increased cerebral vascular resistance (25). In clinical practice, fewer extremely premature infants who receive antenatal steroids require blood pressure support after birth (32).

The effects of antenatal corticosteroids on central nervous system development are complex. Among appropriate for gestational age premature infants, antenatal corticosteroid use is associated with advanced cortical maturation as measured by diffusion tensor imaging at term equivalent age (33). Normally grown, preterm lamb fetuses exhibit transient decreases in carotid flow after maternal antenatal BMZ but Intrauterine growth retardation (IUGR) fetuses and those who have experienced a hypoxic insult have exaggerated cerebral reperfusion which correlates with immunohistochemical evidence of oxidative stress and cerebral apoptosis in the fetal brain $(34,35)$.

While these effects may arise from direct damage to neurons, altered cerebrovascular regulation may also be a contributing factor $(36,37)$. In humans, both BMZ and DEX have been implicated in disturbances in fetal middle cerebral artery (MCA) 


\section{Review | Millagee al.}

flow after single course maternal antenatal steroid administration $(38,39)$. Transient reductions in MCA flow after maternal glucocorticoid administration have been reported in normal human fetuses; prolonged reductions in MCA blood flow have been reported in fetuses $<32 \mathrm{wk}$ of gestation and in the IUGR fetus (38,40-42). A majority of IUGR fetuses (from one-half to two-thirds) transiently respond within 24-96h to antenatal $\mathrm{BMZ}$ as evidenced by reversal of absent end-diastolic flow in the uterine artery (43). However, a subset of severely affected infants show no change in umbilical artery or MCA pulsatility in response to $\mathrm{BMZ}$, and may be at heightened perinatal risk with longer duration of assisted ventilation and supplemental oxygen $(44,45)$.

Long-term assessments of neurodevelopmental outcomes following antenatal exposure to glucocorticoids in humans are lacking in this population of fetuses with severe IUGR. Although meta-analyses report less overall risk of IVH with antenatal steroids; concern has been raised whether this highrisk population should receive antenatal steroids; given the lack of difference in morbidity and mortality between IUGR fetuses that receive antenatal steroids vs. those that do not; and the differential responses of umbilical and cerebral blood flow parameters between IUGR fetuses and those with appropriate intrauterine growth $(46,47)$. In preterm fetuses without growth restriction, there are also reports of an increased risk of neurodevelopmental disability associated with antenatal DEX compared with antenatal BMZ (48).

Antenatal steroid use has been associated with multiorgan vascular effects, which may not manifest until adulthood. For example, antenatal steroid administration improves urinary output in the newborn $(49,50)$. In the kidney, renal blood flow in newborn preterm lambs is improved after single course antenatal BMZ but long-term assessment of these animals reveals an association between antenatal steroid exposure and hypertension and altered renal development in adult life that may be gender-specific (51-53). The adult cerebral circulation of prenatally-exposed sheep to clinically relevant doses of antenatal BMZ exhibits attenuation of pressure-induced vasoconstriction and altered vessel reactivity (54). Fetal programming upon exposure to high dose antenatal (or postnatal) corticosteroids undoubtedly influences the long-term impact of corticosteroids on the developing vascular system and is an important area for further animal and human research.

Human and animal studies using multiple courses of antenatal steroids show that repeated exposure can adversely affect multiple organ systems. Repeated antenatal steroid doses may reduce the severity and frequency of neonatal lung disease in humans but has been associated with decreased fetal growth in some studies $(55,56)$. In lambs, repeat maternal doses of antenatal BMZ cause growth retardation, whereas in utero fetal administration of repeat doses does not alter growth but also demonstrates less improvement in postnatal lung function, suggesting a specific role for maternal metabolism of glucocorticoids in mediating its beneficial effects on the fetus (57). Repeated doses of antenatal BMZ are associated with transient increases in cardiac wall mass at birth though single courses are not $(55,58)$. In the follow-ups between 6 and $8 \mathrm{y}$ of age, there was no difference in cardiovascular risk factors between those who received a single antenatal course of BMZ compared with multiple courses of BMZ (59). Repeated doses of antenatal steroids do not appear to change significantly survival free of major neurologic disability or BMI at 24-month follow-up, although a nonsignificant trend toward more cerebral palsy continues to suggest the need for caution and further research $(60,61)$.

A summary of the vascular effects of antenatal glucocorticoid administration in human and animal research can be found in Table 1.

\section{POSTNATAL VASCULAR EFFECTS}

In vitro experiments in vascular cells and tissues display a dose-dependent response to steroids across multiple experimental endpoints. DEX increases human endothelial cell proliferation and migration and is associated with increased eNOS phosphorylation and cyclic GMP levels after 2-4h of exposure (62). Similar results following acute glucocorticoid exposure have been reported in endothelial cells isolated from multiple species and vascular beds $(1,3,62)$. The common denominator in this effect is the high- dose and short duration of exposure $(<36 \mathrm{~h})$ to corticosteroid. Whether the effect is associated with altered eNOS protein amount, mRNA, or nitric oxide production, this effect is not sustained with long-term corticosteroid treatment, even when a 10 -fold increase in steroid dose is used chronically (63). A glucocorticoid responsive element (GRE) has been reported for eNOS in human umbilical vein endothelial cells and may help to explain the corticosteroid effects on vascular cells (64). Local tissue metabolism of steroids must also be considered when interpreting vascular responses to glucocorticoids. Steroid dehydrogenases, which regenerate and deactivate bioactive forms of endogenous steroids, have been reported to play significant and distinct roles in modulating the effect of glucocorticoids on eNOS (64).

Table 1. Summary of the antenatal effects of glucocorticoids

\begin{tabular}{lllc}
\hline \multirow{2}{*}{ Animal } & Organ system & $\begin{array}{l}\text { In utero } \\
\text { vascular effect }\end{array}$ & References \\
\hline Human & Cardiovascular & & \\
& Ductus venosus & No change & $(41,50)$ \\
& Descending aorta & No change & $(27)$ \\
& Lung Pulmonary artery & Increased flow & $(39)$ \\
& Umbilical artery & Increased flow & $(52)$ \\
& Brain & No change & $(27,41,50,52)$ \\
& MCA & Decreased flow & $(45,46)$ \\
& Other cerebral artery & No change & $(41)$ \\
& or internal carotid & & \\
& Cardiovascular SVR & Increased flow & $(31,51)$ \\
& Renal artery & Increased flow & $(36)$ \\
& Brain & Decreased flow & $(36,52)$ \\
& Lung & Increased flow & $(26,36)$ \\
\hline
\end{tabular}

MCA, middle cerebral artery; SVR, systemic vascular resistance. 


\section{Pulmonary Effects of Postnatal Steroids}

To the neonatologist, the lung is the first litmus test of successful adaptation to extra uterine life. Robust data suggest that steroids have beneficial effects on this organ. The clinical impact of postnatal corticosteroids on lung function is well-recognized. Postnatal steroids (primarily DEX) improve the likelihood of successful extubation and decrease the incidence and severity of chronic lung disease. Some of the early meta-analyses on follow-up data of infants receiving postnatal steroids for chronic lung disease treatment or prevention presented concerning evidence of increased cerebral palsy and poorer neurodevelopmental performance in infants exposed to postnatal steroids. However, more recent reports of low dose postnatal steroids that were started after the first week of life fail to demonstrate adverse effects or benefits at longer follow-up durations $(65,66)$. The potential benefits of postnatal steroids have generally been reserved for the infant at highest risk of pulmonary mortality.

Postnatal steroids seem to offer some protective advantages in animal models of lung inflammation or disease. Adult rabbits chronically exposed to DEX (3-4 d) are protected from the detrimental effects of chronic hypoxia in a model of pulmonary hypertension. DEX treatment prevents the hypoxiainduced decreases in phosphorylation of both eNOS and Akt, a protein kinase that phosphorylates serine 1,177 residues contributing to eNOS activation. In organ-cultured pulmonary arteries of adult rabbits, DEX recovered eNOS mRNA expression and maintained eNOS distribution similar to normoxic controls in hypoxia-induced pulmonary hypertension (13).

\section{Systemic Effects of Postnatal Steroids}

The acute actions of corticosteroids on the systemic circulation appear to have biologic and clinical relevance. Acute effects of eNOS activation are evident in adult disease states and are modulated by high-dose and brief exposure to corticosteroids, effects that are not transcriptionally mediated. Specifically, in adult mouse stroke models, eNOS is involved in the neuroprotective effect of steroids. Endothelial NOS mRNA and protein levels do not acutely change, yet NO generation from eNOS is increased and stroke size is reduced. These rapid, nontranscriptional effects are dose-dependent, exclusive to glucocorticoid receptor activation and are not estrogen or mineralocorticoid receptor-responsive (1). Similarly, in models of myocardial infarction, glucocorticoidmediated reduction in infarction size is not seen in eNOS null mice and is evident only under conditions of high-dose and short-exposure times (3).

In the clinical setting, steroids are used to augment blood pressure, particularly in vasopressor-resistant hypotension (67). Animal models of Cushing syndrome have been used to study the interaction of steroids and blood pressure. Results suggest that these effects are exposure time-dependent. Animal studies show that eNOS is down-regulated at a transcriptional and functional level under chronic glucocorticoid administration $(63,68)$. In these mice models, the decrease in eNOS mRNA and protein in the liver and kidney (with no significant decrease in the heart), correlates with lower tissue amounts of nitrite generation. These studies suggest that proper eNOS function is an important contributor to blood pressure maintenance. Acute, high-dose, short-duration corticosteroids have beneficial effects in ischemic disease states while chronic administration (unrelated to dosage) down regulates eNOS.

Corticosteroids also reduce vascular resistance and increase blood flow in the kidney, heart, and eye $(69,70)$. These effects are thought to be mediated via endothelial-dependent pathways involving vasodilator mediators, including prostaglandin $\mathrm{E}_{2}$ and NO. In adult rats, seven-day treatment with DEX (to prevent cyclosporine-induced nephropathy) produces a marked vasodilatory effect and is associated with increased eNOS (71). Short-term postnatal DEX causes decreased glomerular number and function in adult rats by limiting cell longevity through increased apoptosis (72). In infants treated with postnatal corticosteroids increased retinal blood flow has been noted (73). A subset of neonatal rats exposed to DEX has increased rates of systolic dysfunction as adults (74). However, in humans, a six-week tapering course of postnatal DEX was not associated with altered systolic blood pressure or BMI at school-age follow-up (75).

While the short-term benefits of postnatal steroids on systemic blood pressure in hypotensive neonates were immediately appreciated from clinical experience, the longer-term, neurologic detrimental effects, particularly of prolonged courses of steroids initiated in the first week of life, took longer to be recognized $(12,76,77)$. While there are short-term benefits in several organ systems, the long-term effects of antenatal and postnatal glucocorticoids have yet to be fully elucidated. Table 2 provides a summary of the vascular effects of postnatal glucocorticoids with a breakdown by species, postnatal age, steroid type and organ system.

Table 2. Summary table of the vascular effects of postnatal glucocorticoids

\begin{tabular}{|c|c|c|c|c|c|}
\hline Animal & Age & Steroid & $\begin{array}{l}\text { Organ } \\
\text { system }\end{array}$ & Parameter & References \\
\hline \multirow[t]{3}{*}{ Rat } & \multirow{3}{*}{$\begin{array}{l}\text { Prepuberta } \\
\text { adult }\end{array}$} & \multirow{3}{*}{ DEX } & \multirow{3}{*}{$\begin{array}{l}\text { Heart; } \\
\text { Kidney }\end{array}$} & $\downarrow$ Ventricular weight & (42) \\
\hline & & & & $\uparrow \mathrm{GFR}$ & (72) \\
\hline & & & & $\uparrow$ Apoptosis & (11) \\
\hline \multirow[t]{2}{*}{ Pig } & \multirow{2}{*}{$\begin{array}{l}\text { Term } \\
\text { newborn }\end{array}$} & \multirow[t]{2}{*}{ DEX } & Brain & $\uparrow$ Cerebral BF & (69) \\
\hline & & & Eye & $\uparrow$ Retinal BF & (69) \\
\hline \multirow[t]{6}{*}{ Human } & \multirow{6}{*}{$\begin{array}{l}\text { Preterm } \\
\text { infant }\end{array}$} & \multirow[t]{3}{*}{ DEX } & Brain & $\uparrow$ Cerebral BF & $(70,73)$ \\
\hline & & & Eye & $\uparrow$ Retinal BF & (73) \\
\hline & & & SVR & $\uparrow \mathrm{MABP}$ & (70) \\
\hline & & \multirow[t]{3}{*}{$\mathrm{HCT}$} & Brain & $\begin{array}{l}\text { No change cerebral } \\
\text { BF }\end{array}$ & (67) \\
\hline & & & Kidney & No change renal BF & (67) \\
\hline & & & SVR & $\uparrow M A B P$ & (67) \\
\hline
\end{tabular}

BF, blood flow; DEX, dexamethasone; GFR, glomerular filtration rate; HCT, hydrocortisone; MABP, mean arterial blood pressure; SVR, systemic vascular resistance. 


\section{CONCLUSION}

Glucocorticoids are widely used in perinatal medicine. There is evidence that some of the vascular effects occur via nontranscriptional activation of eNOS. However, the vascular mechanisms of action appear to be dose-, duration- and vascular bed-dependent confounding interpretation of clinical risks and benefits. Data strongly support that antenatal glucocorticoids enhance pulmonary adaptation at birth. There is evidence antenatal steroids cause alterations in fetal systemic vascular tone as well, although the clinical impact of these changes is marginally understood. Postnatal glucocorticoids have beneficial, protective effects in animal models of pulmonary hypertension. Various adult tissue beds also benefit from postnatal steroids in high-dose and short duration, by a mechanism that appears to be nontranscriptionally mediated.

Several gaps remain in our understanding of glucocorticoid effects on the vasculature. The majority of the literature investigates the prenatal effects of glucocorticoids on the pulmonary vascular bed while the brain and gastrointestinal beds of the antenatally exposed fetus and newborn remain largely unexplored. This may be relevant given the protection that is conferred postnatally on these organ systems and the importance of understanding whether it is NOS regulation or other molecular machinery that is responsible for the beneficial effects. Large animal models, such as the neonatal baboon, piglet and lamb possess vascular beds amenable to experimentation that may shed light on the physiological and functional effects of glucocorticoids in the perinatal period while rodent and cell culture studies offer models to explore transcriptional activity, protein activation and downstream signal transduction. Whether findings in these experimental models are translatable to the human neonate is still in question. Inconsistent outcome data have been reported on the impact of antenatal steroid exposure on blood pressure, and vascular stiffness in antenatally exposed adolescents and adults (78-81). Studies on the long-term effects of perinatal glucocorticoid exposure on the cardiovascular system in adulthood are needed both in experimental animal models and in children, while adolescents and adults exposed to glucocorticoids in the perinatal period.

\section{STATEMENT OF FINANCIAL SUPPORT}

The submitting authors have no conflicts of interests to disclose in relation to the work submitted. No financial assistance was received to support this study.

\section{REFERENCES}

1. Limbourg FP, Huang Z, Plumier JC, et al. Rapid nontranscriptional activation of endothelial nitric oxide synthase mediates increased cerebral blood flow and stroke protection by corticosteroids. J Clin Invest 2002;110: 1729-38.

2. Goodwin JE, Zhang J, Geller DS. A critical role for vascular smooth muscle in acute glucocorticoid-induced hypertension. J Am Soc Nephrol 2008;19:1291-9.

3. Hafezi-Moghadam A, Simoncini T, Yang Z, et al. Acute cardiovascular protective effects of corticosteroids are mediated by non-transcriptional activation of endothelial nitric oxide synthase. Nat Med 2002;8:473-9.

4. Fleming I. Biology of nitric oxide synthases. In: Tuma RF, Duran WN, Ley K, eds. Microcirculation. San Diego, CA: Elsevier, 2008: 56-80.
5. Davis CW, Gonzales LW, Ballard RA, Ballard PL, Guo C, Gow AJ. Expression of nitric oxide synthases and endogenous NO metabolism in bronchopulmonary dysplasia. Pediatr Pulmonol 2008;43:703-9.

6. Baytur YB, Ozbilgin K, Yuksel H, Kose C. Antenatal administration of granulocyte-macrophage colony-stimulating factor increases fetal lung maturation and endothelial nitric oxide synthase expression in the fetal rat lung. Eur J Obstet Gynecol Reprod Biol 2008;136:171-7.

7. Okoye BO, Losty PD, Fisher MJ, Wilmott I, Lloyd DA Effect of dexamethasone on endothelial nitric oxide synthase in experimental congenital diaphragmatic hernia. Arch Dis Child Fetal Neonatal Ed 1998;78:F204-8.

8. Chandrasekar I, Eis A, Konduri GG. Betamethasone attenuates oxidant stress in endothelial cells from fetal lambs with persistent pulmonary hypertension. Pediatr Res 2008;63:67-72.

9. Grover TR, Ackerman KG, Le Cras TD, Jobe AH, Abman SH. Repetitive prenatal glucocorticoids increase lung endothelial nitric oxide synthase expression in ovine fetuses delivered at term. Pediatr Res 2000;48:75-83.

10. Caldas JP, Vilela MM, Braghini CA, Mazzola TN, Marba ST. Antenatal maternal corticosteroid administration and markers of oxidative stress and inflammation in umbilical cord blood from very low birth weight preterm newborn infants. J Pediatr (Rio J) 2012;88:61-6.

11. Johns DG, Dorrance AM, Tramontini NL, Webb RC. Glucocorticoids inhibit tetrahydrobiopterin-dependent endothelial function. Exp Biol Med (Maywood) 2001;226:27-31.

12. Yeh TF, Lin YJ, Lin HC, et al. Outcomes at school age after postnatal dexamethasone therapy for lung disease of prematurity. N Engl J Med 2004;350:1304-13.

13. Murata T, Yamawaki H, Hori M, Sato K, Ozaki H, Karaki H. Hypoxia impairs endothelium-dependent relaxation in organ cultured pulmonary artery. Eur J Pharmacol 2001;421:45-53.

14. Benediktsson R, Calder AA, Edwards CR, Seckl JR. Placental 11 betahydroxysteroid dehydrogenase: a key regulator of fetal glucocorticoid exposure. Clin Endocrinol (Oxf) 1997;46:161-6.

15. Roberts D, Dalziel S Antenatal corticosteroids for accelerating fetal lung maturation for women at risk of preterm birth. Cochrane Database Syst Rev 2006:CD004454.

16. Liggins GC, Howie RN. A controlled trial of antepartum glucocorticoid treatment for prevention of the respiratory distress syndrome in premature infants. Pediatrics 1972;50:515-25.

17. Opinion AC Antenatal corticosteroid therapy for fetal maturation. Obstet Gynecol 2002;99:871-3.

18. Carlo WA, McDonald SA, Fanaroff AA, et al.; Eunice Kennedy Shriver National Institute of Child Health and Human Development Neonatal Research Network. Association of antenatal corticosteroids with mortality and neurodevelopmental outcomes among infants born at 22 to 25 weeks' gestation. JAMA 2011;306:2348-58.

19. Gyamfi-Bannerman C, Thom EA, Blackwell SC, et al.; NICHD MaternalFetal Medicine Units Network. Antenatal betamethasone for women at risk for late preterm delivery. N Engl J Med 2016;374:1311-20.

20. Derderian SC, Coleman AM, Jeanty C, et al. Favorable outcomes in highrisk congenital pulmonary airway malformations treated with multiple courses of maternal betamethasone. J Pediatr Surg 2015;50:515-8.

21. Ikegami M, Polk D, Jobe A. Minimum interval from fetal betamethasone treatment to postnatal lung responses in preterm lambs. Am J Obstet Gynecol 1996;174:1408-13.

22. Cuevas Guaman M, Sbrana E, Shope C, et al. Administration of antenatal glucocorticoids and postnatal surfactant ameliorates respiratory distress syndrome-associated neonatal lethality in Erk3(-/-) mouse pups. Pediatr Res 2014;76:24-32.

23. Collins JJ, Kunzmann S, Kuypers E, et al. Antenatal glucocorticoids counteract LPS changes in TGF- $\beta$ pathway and caveolin-1 in ovine fetal lung. Am J Physiol Lung Cell Mol Physiol 2013;304:L438-44.

24. Deruelle P, Houfflin-Debarge V, Magnenant E, et al. Effects of antenatal glucocorticoids on pulmonary vascular reactivity in the ovine fetus. Am J Obstet Gynecol 2003;189:208-15.

25. Crossley KJ, Morley CJ, Allison BJ, et al. Antenatal corticosteroids increase fetal, but not postnatal, pulmonary blood flow in sheep. Pediatr Res 2009;66:283-8. 


\section{Perinatal steroids and the vasculature}

26. Suzuki K, Hooper SB, Wallace MJ, Probyn ME, Harding R. Effects of antenatal corticosteroid treatment on pulmonary ventilation and circulation in neonatal lambs with hypoplastic lungs. Pediatr Pulmonol 2006;41: $844-54$.

27. Bartha JL, Largo-Heinrich M, Machado MJ, González-Bugatto F, HervíasVivancos B. Effects of antenatal betamethasone on human fetal branch pulmonary artery flow velocity waveforms. Fetal Diagn Ther 2008;23:46-53.

28. Cohlen BJ, Stigter RH, Derks JB, Mulder EJ, Visser GH. Absence of significant hemodynamic changes in the fetus following maternal betamethasone administration. Ultrasound Obstet Gynecol 1996;8:252-5.

29. Lunshof MS, Boer K, Wolf H, Koppen S, Velderman JK, Mulder EJ. Shortterm $(0-48 \mathrm{~h})$ effects of maternal betamethasone administration on fetal heart rate and its variability. Pediatr Res 2005;57:545-9.

30. Clifton VL, Wallace EM, Smith R. Short-term effects of glucocorticoids in the human fetal-placental circulation in vitro. J Clin Endocrinol Metab 2002;87:2838-42.

31. Ervin MG, Padbury JF, Polk DH, Ikegami M, Berry LM, Jobe AH. Antenatal glucocorticoids alter premature newborn lamb neuroendocrine and endocrine responses to hypoxia. Am J Physiol Regul Integr Comp Physiol 2000;279:R830-8.

32. Moïse AA, Wearden ME, Kozinetz CA, Gest AL, Welty SE, Hansen TN. Antenatal steroids are associated with less need for blood pressure support in extremely premature infants. Pediatrics 1995;95:845-50.

33. Pogribna U, Yu X, Burson K, et al. Perinatal clinical antecedents of white matter microstructural abnormalities on diffusion tensor imaging in extremely preterm infants. PLoS One 2013;8:e72974.

34. Miller SL, Chai M, Loose J, et al. The effects of maternal betamethasone administration on the intrauterine growth-restricted fetus. Endocrinol 2007;148:1288-95.

35. Koome ME, Davidson JO, Drury PP, et al. Antenatal dexamethasone after asphyxia increases neural injury in preterm fetal sheep. PLoS One 2013;8:e77480.

36. Miller SL, Supramaniam VG, Jenkin G, Walker DW, Wallace EM. Cardiovascular responses to maternal betamethasone administration in the intrauterine growth-restricted ovine fetus. Am J Obstet Gynecol 2009;201:613. e1-8.

37. Vinukonda G, Dummula K, Malik S, et al. Effect of prenatal glucocorticoids on cerebral vasculature of the developing brain. Stroke 2010;41:1766-73.

38. Urban R, Lemancewicz A, Przepieść J, Urban J, Kretowska M. Antenatal corticosteroid therapy: a comparative study of dexamethasone and betamethasone effects on fetal Doppler flow velocity waveforms. Eur J Obstet Gynecol Reprod Biol 2005;120:170-4.

39. Müller T, Nanan R, Dietl J. Effect of antenatal corticosteroid administration on Doppler flow velocity parameters in pregnancies with absent or reverse end-diastolic flow in the umbilical artery. Acta Obstet Gynecol Scand 2003;82:794-6.

40. Wijnberger LD, Bilardo CM, Hecher K, Stigter RH, Visser GH. Effect of antenatal glucocorticoid therapy on arterial and venous blood flow velocity waveforms in severely growth-restricted fetuses. Ultrasound Obstet Gynecol 2004;23:584-9.

41. Senat MV, Ville Y. Effect of steroids on arterial Doppler in intrauterine growth retardation fetuses. Fetal Diagn Ther 2000;15:36-40.

42. Piazze JJ, Anceschi MM, La Torre R, Amici F, Maranghi L, Cosmi EV. Effect of antenatal betamethasone therapy on maternal-fetal Doppler velocimetry. Early Hum Dev 2001;60:225-32.

43. Nozaki AM, Francisco RP, Fonseca ES, Miyadahira S, Zugaib M. Fetal hemodynamic changes following maternal betamethasone administration in pregnancies with fetal growth restriction and absent end-diastolic flow in the umbilical artery. Acta Obstet Gynecol Scand 2009;88:350-4.

44. Simchen MJ, Alkazaleh F, Adamson SL, et al. The fetal cardiovascular response to antenatal steroids in severe early-onset intrauterine growth restriction. Am J Obstet Gynecol 2004;190:296-304.

45. Robertson MC, Murila F, Tong S, Baker LS, Yu VY, Wallace EM. Predicting perinatal outcome through changes in umbilical artery Doppler studies after antenatal corticosteroids in the growth-restricted fetus. Obstet Gynecol 2009;113:636-40.
46. Torrance HL, Derks JB, Scherjon SA, Wijnberger LD, Visser GH. Is antenatal steroid treatment effective in preterm IUGR fetuses? Acta Obstet Gynecol Scand 2009;88:1068-73.

47. van Stralen G, van der Bos J, Lopriore E, et al. No short-term benefits of antenatal corticosteroid treatment in severely preterm growth restricted fetuses: a case-control study. Early Hum Dev 2009;85:253-7.

48. Lee BH, Stoll BJ, McDonald SA, Higgins RD; National Institute of Child Health and Human Development Neonatal Research Network. Neurodevelopmental outcomes of extremely low birth weight infants exposed prenatally to dexamethasone versus betamethasone. Pediatrics 2008;121: 289-96.

49. Omar SA, DeCristofaro JD, Agarwal BI, La Gamma EF. Effects of prenatal steroids on water and sodium homeostasis in extremely low birth weight neonates. Pediatrics 1999;104(3 Pt 1):482-8.

50. Ervin MG, Berry LM, Ikegami M, Jobe AH, Padbury JF, Polk DH. Single dose fetal betamethasone administration stabilizes postnatal glomerular filtration rate and alters endocrine function in premature lambs. Pediatr Res 1996;40:645-51.

51. Berry LM, Polk DH, Ikegami M, Jobe AH, Padbury JF, Ervin MG. Preterm newborn lamb renal and cardiovascular responses after fetal or maternal antenatal betamethasone. Am J Physiol 1997;272(6 Pt 2):R1972-9.

52. Figueroa JP, Rose JC, Massmann GA, Zhang J, Acuña G. Alterations in fetal kidney development and elevations in arterial blood pressure in young adult sheep after clinical doses of antenatal glucocorticoids. Pediatr Res 2005;58:510-5.

53. Tang L, Carey LC, Bi J, et al. Gender differences in the effects of antenatal betamethasone exposure on renal function in adult sheep. Am J Physiol Regul Integr Comp Physiol 2009;296:R309-17.

54. Eckman DM, Kerr BA, Fuloria M, et al. Antenatal betamethasone alters vascular reactivity in adult female ovine cerebral arteries. Pediatr Res 2010;68:344-8.

55. Crowther CA, Harding JE Repeat doses of prenatal corticosteroids for women at risk of preterm birth for preventing neonatal respiratory disease. Cochrane Database Syst Rev 2007:CD003935.

56. Murphy KE, Willan AR, Hannah ME, et al.; Multiple Courses of Antenatal Corticosteroids for Preterm Birth Study Collaborative Group. Effect of antenatal corticosteroids on fetal growth and gestational age at birth. Obstet Gynecol 2012;119:917-23.

57. Jobe AH, Newnham J, Willet K, Sly P, Ikegami M. Fetal versus maternal and gestational age effects of repetitive antenatal glucocorticoids. Pediatrics 1998;102:1116-25.

58. Vural M, Yilmaz I, Oztunc F, Ilikkan B, Erginoz E, Perk Y Cardiac effects of a single course of antenatal betamethasone in preterm infants. Arch Dis Child Fetal Neonatal Ed 2006;91:F118-22.

59. McKinlay CJ, Cutfield WS, Battin MR, Dalziel SR, Crowther CA, Harding JE; ACTORDS Study Group. Cardiovascular risk factors in children after repeat doses of antenatal glucocorticoids: an RCT. Pediatrics 2015;135:e405-15.

60. Wapner RJ, Sorokin Y, Mele L, et al.; National Institute of Child Health and Human Development Maternal-Fetal Medicine Units Network. Long-term outcomes after repeat doses of antenatal corticosteroids. N Engl J Med 2007;357:1190-8.

61. Asztalos EV, Murphy KE, Willan AR, et al.; MACS-5 Collaborative Group. Multiple courses of antenatal corticosteroids for preterm birth study: outcomes in children at 5 years of age (MACS-5). JAMA Pediatr 2013;167:1102-10.

62. Polytarchou C, Papadimitriou E. Antioxidants inhibit human endothelial cell functions through down-regulation of endothelial nitric oxide synthase activity. Eur J Pharmacol 2005;510:31-8.

63. Wallerath T, Gödecke A, Molojavyi A, Li H, Schrader J, Förstermann U. Dexamethasone lacks effect on blood pressure in mice with a disrupted endothelial NO synthase gene. Nitric Oxide 2004;10:36-41.

64. Liu Y, Mladinov D, Pietrusz JL, Usa K, Liang M. Glucocorticoid response elements and 11 beta-hydroxysteroid dehydrogenases in the regulation of endothelial nitric oxide synthase expression. Cardiovasc Res 2009;81: $140-7$. 
65. O'Shea TM, Washburn LK, Nixon PA, Goldstein DJ. Follow-up of a randomized, placebo-controlled trial of dexamethasone to decrease the duration of ventilator dependency in very low birth weight infants: neurodevelopmental outcomes at 4 to 11 years of age. Pediatrics 2007;120:594-602.

66. Doyle LW, Davis PG, Morley CJ, McPhee A, Carlin JB; DART Study Investigators. Outcome at 2 years of age of infants from the DART study: a multicenter, international, randomized, controlled trial of low-dose dexamethasone. Pediatrics 2007;119:716-21.

67. Noori S, Friedlich P, Wong P, Ebrahimi M, Siassi B, Seri I. Hemodynamic changes after low-dosage hydrocortisone administration in vasopressortreated preterm and term neonates. Pediatrics 2006;118:1456-66.

68. Schäfer SC, Wallerath T, Closs EI, et al. Dexamethasone suppresses eNOS and CAT- 1 and induces oxidative stress in mouse resistance arterioles. Am J Physiol Heart Circ Physiol 2005;288:H436-44.

69. Stiris TA, Blanco D, Codoceo R, et al. Effects of dexamethasone on retinal and choroidal blood flow during normoxia and hyperoxia in newborn piglets. Pediatr Res 1996;40:592-6.

70. Pellicer A, Gaya F, Stiris TA, Quero J, Cabanas F Cerebral haemodynamics in preterm infants after exposure to dexamethasone. Arch Dis Child Fetal Neonatal Ed 1998;79:F123-8.

71. Bobadilla NA, Tapia E, Jiménez F, et al. Dexamethasone increases eNOS gene expression and prevents renal vasoconstriction induced by cyclosporin. Am J Physiol 1999;277(3 Pt 2):F464-71.

72. de Vries WB, van den Borne P, Goldschmeding R, et al. Neonatal dexamethasone treatment in the rat leads to kidney damage in adulthood. Pediatr Res 2010;67:72-6.

73. Cabañas F, Pellicer A, García-Alix A, Quero J, Stiris TA. Effect of dexamethasone therapy on cerebral and ocular blood flow velocity in premature infants studied by colour Doppler flow imaging. Eur J Pediatr 1997; 156:41-6.

74. Bal MP, de Vries WB, van Oosterhout MF, et al. Long-term cardiovascular effects of neonatal dexamethasone treatment: hemodynamic follow-up by left ventricular pressure-volume loops in rats. J Appl Physiol (1985) 2008;104:446-50.

75. Washburn LK, Nixon PA, O'Shea TM. Follow-up of a randomized, placebo-controlled trial of postnatal dexamethasone: blood pressure and anthropometric measurements at school age. Pediatrics 2006;118: 1592-9.

76. Barrington KJ. The adverse neuro-developmental effects of postnatal steroids in the preterm infant: a systematic review of RCTs. BMC Pediatr 2001;1:1.

77. Doyle LW, Ehrenkranz RA, Halliday HL Late (> 7 days) postnatal corticosteroids for chronic lung disease in preterm infants. Cochrane Database Syst Rev 2014;5:CD001145.

78. Dalziel SR, Walker NK, Parag V, et al. Cardiovascular risk factors after antenatal exposure to betamethasone: 30-year follow-up of a randomised controlled trial. Lancet 2005;365:1856-62.

79. Dessens AB, Haas HS, Koppe JG. Twenty-year follow-up of antenatal corticosteroid treatment. Pediatrics 2000;105:E77.

80. Doyle LW, Ford GW, Davis NM, Callanan C. Antenatal corticosteroid therapy and blood pressure at 14 years of age in preterm children. Clin Sci (Lond) 2000;98:137-42.

81. Kelly BA, Lewandowski AJ, Worton SA, et al. Antenatal glucocorticoid exposure and long-term alterations in aortic function and glucose metabolism. Pediatrics 2012;129:e1282-90. 